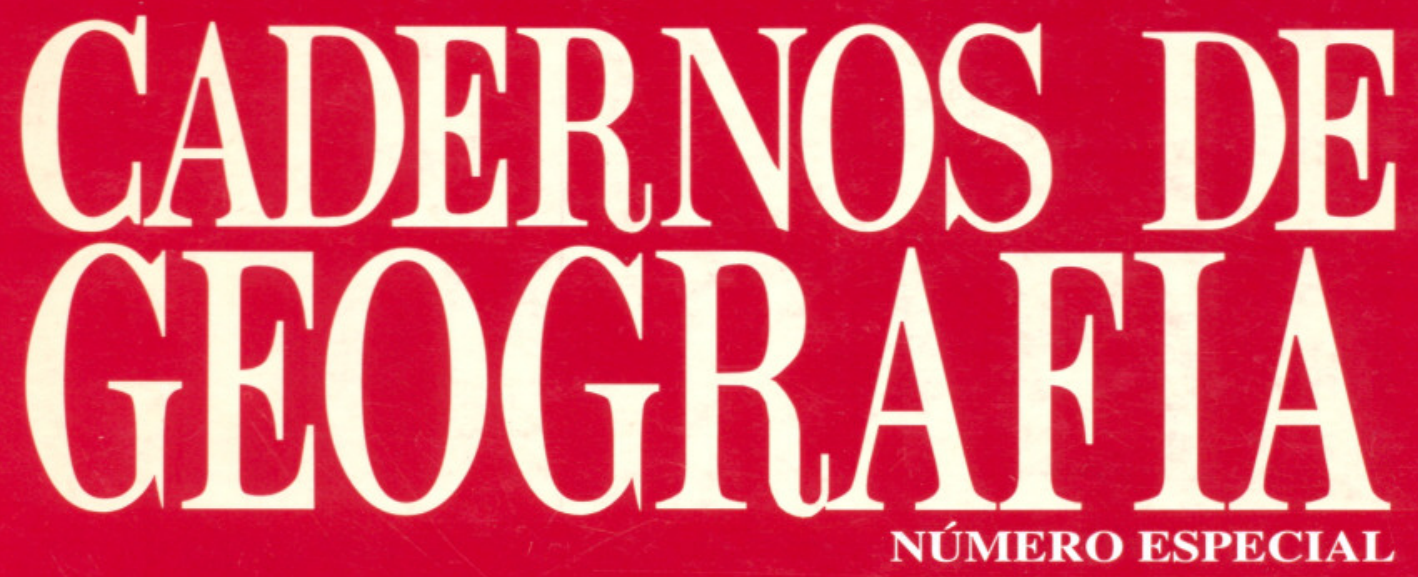

INSTITUTO DE ESTUDOS GEOGRÁFICOS com a colaboração do Centro de Estudos Geográficos

FACULDADE DE LETRAS - UNIVERSIDADE DE COIMBRA

ACTAS DO SEGUNDO COLÓQUIO DE GEOGRAFIA DE COIMBRA COIMBRA 1999

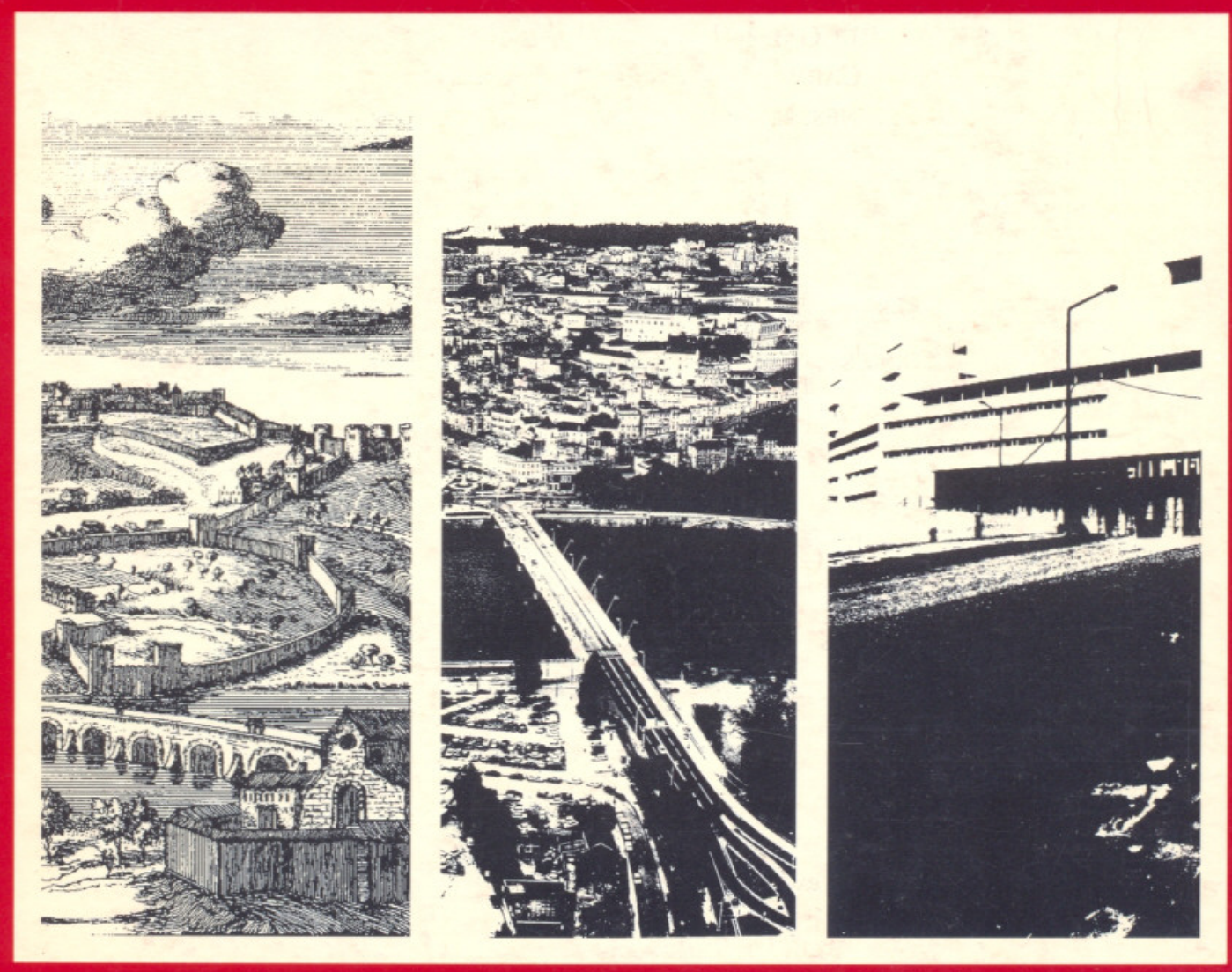




\section{A INFLUÊNCIA DO CLIMA NA PRODUÇÃO VITIVINÍCOLA ANUAL}

Adélia Nunes

António Vieira

A cultura da vinha faz parte integrante da nossa História, perdendo-se no tempo as suas origens. Da diversidade climática, morfológica e pedológica regional nasceram habitats particulares que permitiram o desenvolvimento de castas e a produção de vinhos com composições organolépticas diferenciadas.

Não obstante, a produção vitícola anual é determinada por um complexo quadro onde interferem diversos factores, agrupados frequentemente em: mesológicos (solo, clima, altitude e exposição); humanos (opções do agricultor, preparação do terrenos, encepamento); regulamentares (castas autorizadas, produtos enológicos permitidos) e ainda de natureza económica (por exemplo a procura dos mercados vinícolas nacionais e internacionais).

Ao factor clima é, quase sempre, imputado um papel preponderante quer pela actuação directa exercida sobre fisiologia da videira quer, e em particular, na fotossíntese. As flutuações anuais no rendimento das castas (tanto em qualidade como em quantidade) são quase sempre relacionadas com as variações de tempo, caracterizantes do clima mediterrâneo. É que a videira tal como as outras plantas tem exigências particulares em relação ao meio em que vive, sobretudo pela acção de três elementos climáticas fundamentais: temperatura, humidade e luminosidade.

O seu ciclo vegetativo e reprodutor, composto por uma sucessão de estados fenológicos: abrolhamento, floração, pintor e maturação, só se concretiza através da acumulação de certa quantidade de calor, verificando-se que após o abrolhamento a floração não terá lugar se não for atingido o somatório de uma certa temperatura acumulada, dado pela média diária; o mesmo se verifica relativamente às fases subsequentes.

Nestes termos e com o objectivo de averiguar a influência do factor clima (temperatura e precipitação) na produção vinícola anual, procedemos à análise de duas situações: uma relacionada com a quantidade anual e outra com a qualidade final dos mostos, em duas regiões demarcadas, a da Bairrada (R.D.B) e a do Douro (R.D.D).

\section{A produção vitivinícola da Bairrada}

O problema da baixa de produtividade têm-se vindo a verificar e a arrastar ao longo dos anos na R.D.B, devido principalmente ao envelhecimento dos vinhedos e às dificuldades de mecanização. No entanto, a análise das produções anuais dos anos compreendidos entre 1984 e 1996, mostra oscilações por vezes acentuadas, que nos permitem questionar a influência destas variáveis no desenvolvimento das castas. A alternância de anos de produção elevada com outros de menor rendimento sugerem-nos o clima como um dos principais factores explicativos desta desigual produtividade.

Nesta perspectiva, selecionámos dois anos de entre o período indicado: um de produção vitivinícola elevada, $1990(649730 \mathrm{HI})$; e outro de fracos quantitativos vinícola, $1993(189820 \mathrm{HI})$.

Seguidamente, procedemos à análise dos elementos climáticos, temperatura e precipitação, visto que em certos momentos do desenvolvimento da vinha, poderão ter tido um efeito nefasto sobre as castas, prejudicando o seu crescimento e, consequentemente, a sua produtividade.

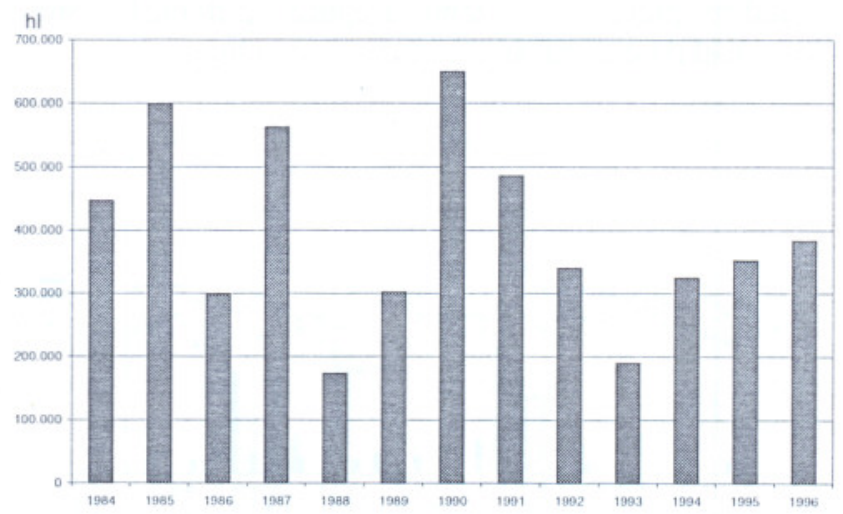

Fig. 1- Produção de vinhos na Bairrada (1984-96)

Da observação dos referidos elementos podemos concluir que, no respeitante à temperatura, o ano de 1993 , de menor produtividade, registou um elevado número de dias com temperaturas inferiores a $5^{\circ} \mathrm{C}$, ocorrendo, inclusivamente, valores térmicos negativos em vários dias. Tal situação contribuiu, certamente, para um retardamento da actividade celular e para um atraso no desenvolvimento da vinha.

Comparativamente o ano de 1990, com produções superiores, registou igualmente dias com temperatura 
inferior a $5^{\circ} \mathrm{C}$ mas em menor número, pelo que a sua ocorrência não terá afectado o desenvolvimento da vinha. A média mensal ligeiramente acima do valor relativo a 1993, traduziu-se por maiores quantitativos de energia recebida, altamente favorecedores do crescimento e desenvolvimento das vinhas.

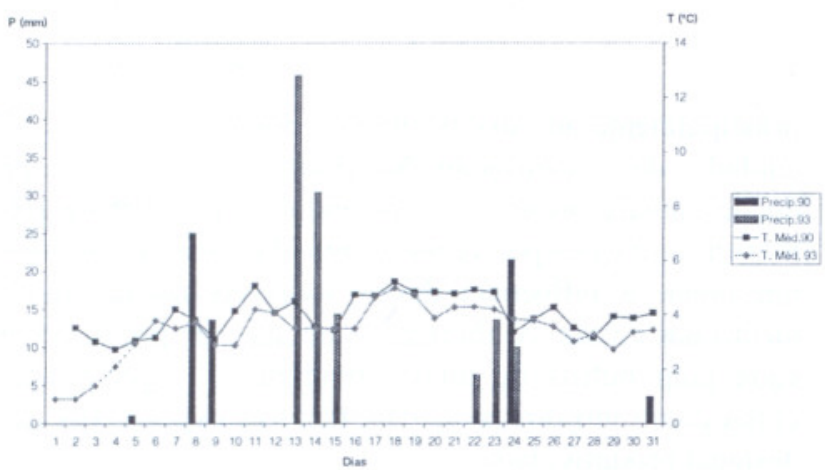

Fig.2- Temperatura e precipitação em Março (abrolhamento) nos anos de 1990 e 1993

No respeitante à precipitação, o ano de menor produção vinícola denotou valores relativamente mais elevados, nomeadamente nos períodos considerados como mais críticos, pois a videira estaria mais vulnerável à actuação deste elemento. Em 1993, a precipitação concentrou-se nos meses de Abril-Maio e SetembroOutubro, prejudicando tanto a época de floração como a fase final da maturação e as próprias vindimas.

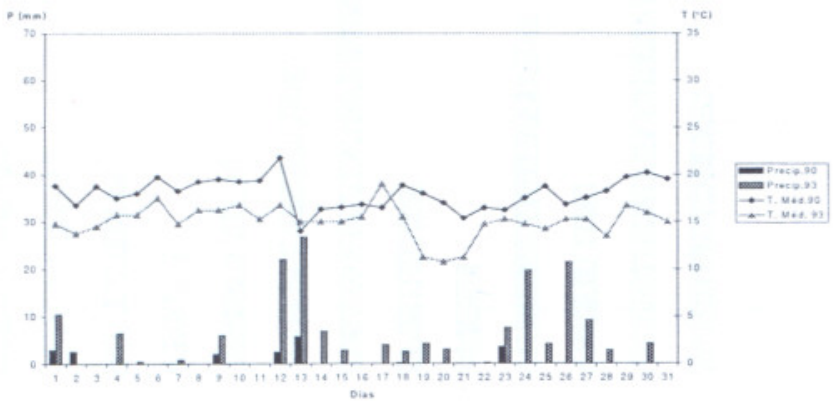

Fig. 3 - Temperatura média e precipitação em Setembro (maturação) nos anos de 1990 e 1993

A produção final terá sido, assim, bastante afectada pela pluviosidade que se verificou, repercutindo-se no apodrecimento das uvas. Em 1990, a concentração da chuva em Fevereiro e Abril, parece não ter interferido no desenvolvimento da vinha. Por outro lado, a ocorrência de curtos períodos de precipitação em Setembro revelou-se benéfico enquanto que em Outubro, especialmente após o dia 14, as fortes chuvadas não terão influenciado as colheitas, uma vez que a maioria dos viticultores já tinham realizado as vindimas.

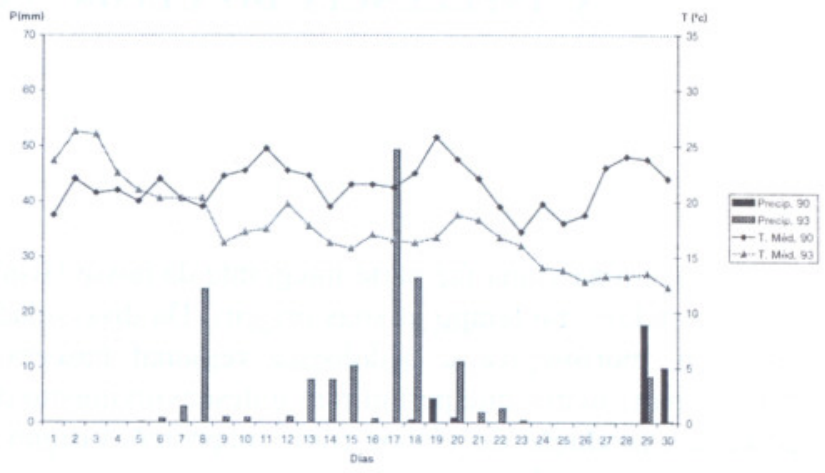

Fig. 4- Temperatura média e precipitação em Setembro (maturação) nos anos de 1990 e 1993

\section{A qualidade dos vinhos do Porto Vintage (R.D.D.)}

O Porto Vintage é um tipo de vinho relativamente pouco conhecido pelo consumidor portugês. Os mais entendidos enólogos descrevem-no como um "vinho licoroso de cor muito escura, aroma e sabores intensos que se faz com as melhores uvas de uma só colheita, produzidas no vale duriense, na Região Demarcada do Douro".

A proposição de um vinho para a classificação de Vintage obedece a um conjunto de normas essenciais estipuladas pelo Instituto do Vinho do Porto (desde a vinificação, conservação, envelhecimento, produtos enológicos permitidos) sendo permissível a sua declaração sempre que os padrões de qualidade máxima sejam atingidos.

A apresentação anual de um desigual número de Vintages suscitou-nos particular interesse, investigando-se para o efeito a influência simultânea da temperatura e da precipitação (por períodos de 10 dias) em dois anos cujo número de Vintages propostos foi substancialmente discrepante: o ano de 1981 com apenas I casa a declarar Vintage e o de 1991 com 41 proposições, sabendo-se no entanto, que a média térmica (calculada para o período fenológico da videira - Janeiro a Outubro) foi idêntica $\left(17,1^{\circ} \mathrm{C}\right)$ e a pluviosidade total apenas diferiu em $34 \mathrm{~mm}$, a favor do ano classificado como Vintage.

Portanto, as correlações entre a qualidade final dos mostos e os valores médios da temperatura e totais de precipitação não se revelam evidentes e os condicionalismos climáticos só poderão adquirir algum significado quando considerada a variabilidade intra-anual, sobressaindo da sua análise a falta de sintonia em determinados 
períodos do ciclo vegetativo da videira. As principais nuances, obtidas do confronto do regime termopluviométrico entre o ano de 1981 e o de 1991, afectam dois períodos fundamentais: a floração e a maturação.

Efectivamente, a falta de sincronia na evolução das temperaturas e no comportamento das precipitações no decurso do abrolhamento e depois na floração, revelou-se através de uma maior variabilidade térmica e por quantitativos pluviométricos ligeiramente mais elevados no ano não vintage (1981) comparativamente ao vintage (1991). As chuvas ocorridas nos meses de Abril e Maio de 1981 terão impedido o crescimento normal das inflorescências e ulteriormente a fecundação das flores pelas dificuldades impostas à queda do capuz e ao transporte de pólen.

Aliás, o contexto climático menos propício ao desenvolvimento das videiras, constante durante a época de floração (mês de Maio) manteve-se até à fase final de maturação (finais de Setembro e inícios de Outubro) determinando algumas perturbações fisiológicas nas castas. A continua necessidade de proteger as videiras contra o míldio e o oídio desencadearam várias interven- ções fitosanitárias com efeito óbvio no potencial qualitativo final, prejudicado ainda pelas intensas chuvadas ocorridas por altura das vindimas. Esta exagerada alimentação hídrica conjugada com temperaturas significativamente mais baixas terão contribuído para a diluição dos compostos gustativos dos bagos, definidores de um Porto Vintage.

Contrariamente, a superioridade térmica observada no decurso da floração e, muito especialmente, na recta final de maturação $\left(4^{\circ} \mathrm{C}\right)$ associada a esporádicos períodos de chuva terão, em 1991, determinado uma maior acumulação de açúcares, frutose e glucose, e suavizado a acidez das uvas contemplando, necessariamente, a qualidade final dos mostos.

\section{Conclusão}

$\mathrm{O}$ maior ou menor rendimento, bem como a maior ou menor concentração de elementos nobres expressivos da qualidade estão, obviamente, dependentes das condições climáticas, sobretudo se tivermos em atenção que esta

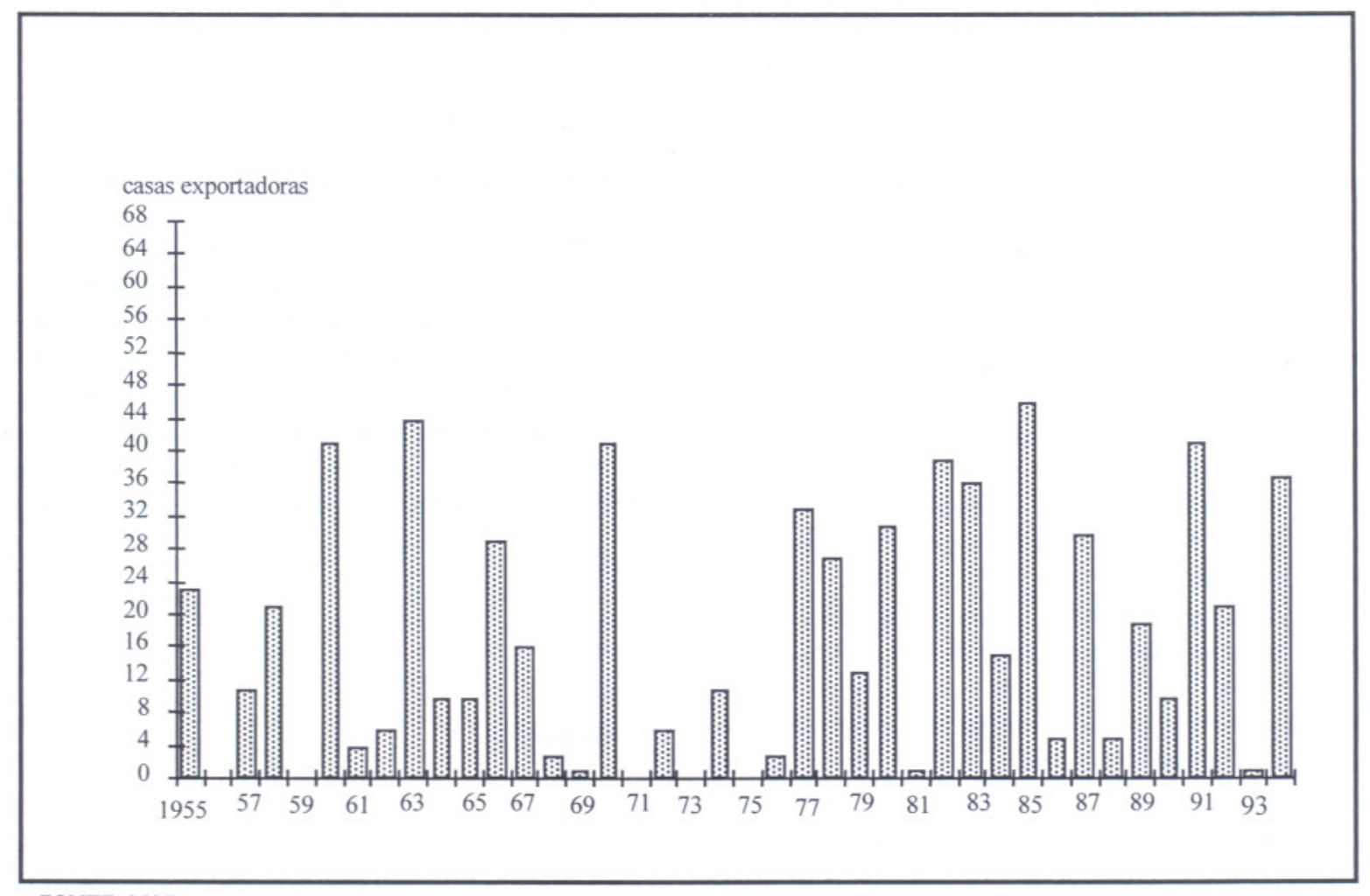

FONTE: I.V.P.

Fig. 5 - Número de declarações de vintage de 1955 a 1994 

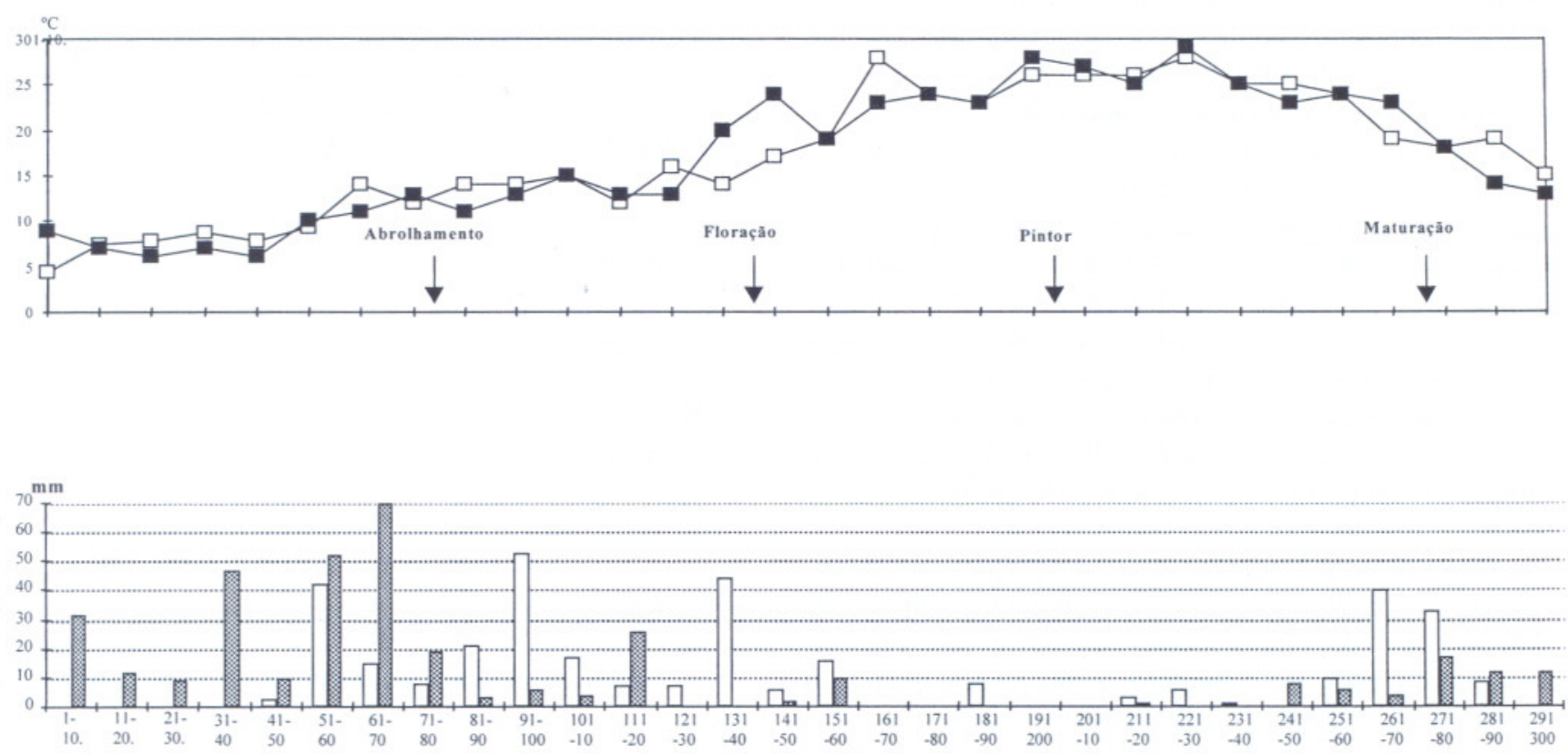

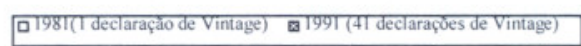

Fig. 6 - Evolução das temperaturas médias e totais de precipitação, por periodo de 10 dias, nos anos de 1981 e 1991 , de Janeiro a Outubro, e datas médias para cada fase do ciclo vegetativo da videira

variável é a mais dinâmica da multiplicidade de factores intervenientes na composição final dos mostos.

As correlações entre a quantidade/qualidade dos vinhos e os condicionalismos climáticos parecem incontestáveis, interferindo sobretudo, em dois períodos particulares das castas: floração e maturação. A falta de simultaneidade no regime termopluviométrico para os 4 anos em análise manifestou-se sobretudo, por valores de precipitação mais elevados e por temperaturas relativamente mais baixas nos anos de 1981 e 1990, ao passo que o de 1993 face à evolução térmica positiva e às menores pluviosidades, em especial nos períodos anteriormente referidos, terão incrementado a produção e valorizado a qualidade final dos mostos. Quanto às vindimas, embora não se integrem no ciclo da videira, parecem deter um papel primordial na produção final pois não é indiferente a sua realização com bom ou mau tempo.

Embora as correlações se evidenciem particularmente estreitas, os 4 anos que constituiram objecto de estudo, são claramente insuficientes para o estabelecimento de um padrão comportamental capaz de distrinçar os bons anos dos de menor produtividade; tornar-se-ia necessário a observação de um período consideravelmente mais alargado.

Por outro lado, para a melhor compreensão da complexidade inerente à declaração de um Vintage e totais anuais produzidos, seria imprescendível o alargamento dos factores de pesquisa. Por um lado, explorando outras variáveis climatológicas tais como a humidade relativa do ar, insolação e velocidade do vento, bem como outras da mesma natureza (relevo, exposição) ou de natureza diferente (humanas, económicas e culturais).

\section{Bibliografia}

Alcoforado, M. J. (1992) - Clima de Portugal- diversidade climática de Portugal Continental, Portugal ModernoGeografia, Enciclopédia Temática, Ed. Pomo.

Almeida, M. J. (1958) - Região Demarcada do Douro - Vinho do Porto. 
ARNALDO, L. S. (1985) - Contribuição para o conhecimento e estudo do vinho de pasto da região Demarcada do Douro, Rel. Estágio. Universidade de Trás-os-Montes, Vila Real.

Bettencourt, M. L. (1982) - Algumas notas sobre a fenologia e a sua importância no estudo do Clima, Revista do I.N.M.G.. Vol. 5, $\mathrm{N}^{\circ} 1$ a 4 , Jan/Dez.

Bravo, P.; Oliveira D. (1974) - l'iticultura moderna, Livraria Almedina. Coimbra.
Chavennet, M.: RAynier, A: (1979) - Manual de viticultura. Biblioteca Agrícola, Litexa.

FEIO, M. (1991)- Clima e agricultura, Lisboa.

FerreirA, D. B. (1993) - Agroclimatologia, Centro de Estudos Geográficos, Lisboa.

HuFTY, A (1984) - Introduction a la climatologie. 